\title{
Erratum to: Defining Treatment Response and Symptom Remission for Anxiety Disorders in Pediatric Autism Spectrum Disorders Using the Pediatric Anxiety Rating Scale
}

\author{
Carly J. Johnco $^{1,2}(\mathbb{D}) \cdot$ Alessandro S. De Nadai $^{3}$ - Adam B. Lewinn ${ }^{1,3,4}$. \\ Jill Ehrenreich-May ${ }^{5}$ Jeffrey J. Wood ${ }^{6,7} \cdot$ Eric A. Storch ${ }^{1,3,4,8,9,10}$
}

Published online: 14 August 2015

(C) Springer Science+Business Media New York 2015

\section{Erratum to: J Autism Dev Disord DOI 10.1007/s10803-015-2483-9}

The original version of the article unfortunately contained an error in funding information of the second author. This erratum is to correct the error.

Alessandro De Nadai receives funding from the National Institutes of Health under National Institute of Mental Health Grant F31 MH094095.

The online version of the original article can be found under doi:10.1007/s10803-015-2483-9.

Carly J. Johnco

cjohnco@health.usf.edu

1 Department of Pediatrics, University of South Florida, St. Petersburg, FL, USA

2 Rothman Center for Pediatric Neuropsychiatry, Child Development and Rehabilitation Center, 880 6th Street South Suite 460, Box 7523, St. Petersburg, FL 33701, USA

3 Department of Psychology, University of South Florida, Tampa, FL, USA

4 Department of Psychiatry and Behavioral Neurosciences, University of South Florida, Tampa, FL, USA

5 Department of Psychology, University of Miami, Miami, FL, USA
6 Division of Child Psychiatry, University of California, Los Angeles, CA, USA

7 Division of Psychological Studies in Education, University of California, Los Angeles, CA, USA

8 Department of Health Policy and Management, University of South Florida, Tampa, FL, USA

9 Rogers Behavioral Health - Tampa Bay, Tampa, FL, USA

10 All Children's Hospital - Johns Hopkins Medicine, St. Petersburg, FL, USA 